\title{
Vegetação ripária e métodos de estudo
}

Esta revisão bibliográfica compara alguns termos utilizados para se referir à vegetação marginal que ocorre ao longo de cursos de água, concluindo que o termo "ripário" é o mais adequado, pois significa "próximo ao curso de água", tratando de conceitos de distância e água. A vegetação ripária tem várias funções de proteção, dentre elas, a proteção dos solos ribeirinhos contra a erosão. É considerada de grande importância, pois retém impurezas, preservando a integridade das águas. Deve-se ainda somar a esta função da floresta ripária a hidrológica, representada por processos importantes para a estabilidade da microbacia, para a manutenção da quantidade e qualidade da água e para a manutenção do ecossistema aquático. Uma das características das vegetações ripárias é a heterogeneidade ambiental que se repete dentro de diferentes domínios vegetacionais, e acabam por definir diferentes métodos para o estudo das vegetações ripárias, estudos estes como o da fenologia de plantas, fundamental em qualquer plano vegetacional; o estudo fitossociológico, que possibilita a avaliação da estrutura e composição da vegetação; o florístico, estudo inicial para o conhecimento da flora; o dendrométrico, que trata da medição de árvores, tanto do ponto de vista individual quanto do coletivo; e o dendrológico, que tem como base conhecer as espécies a partir de regiões específicas, dando condições para o conhecimento da constituição arbórea de uma determinada comunidade vegetacional. Portanto, este trabalho teve por finalidade, realizar uma revisão bibliográfica apresentando as principais definições de "vegetação ripária", suas funções e métodos de estudo para conservação.

Palavras-chave: Floresta ripária; Funções; Métodos para estudo.

\section{Riparian vegetation and methods of study}

\begin{abstract}
This bibliographical review compares some terms used to refer to the marginal vegetation that occurs along water courses, concluding that the term "riparian" is the most appropriate, because it means "near the watercourse", dealing with distance and Water. Riparian vegetation has several protection functions, among them, the protection of riverside soils against erosion. It is considered of great importance, because it retains impurities, preserving the integrity of the waters. It is also necessary to add to this function of the riparian forest the hydrological one, represented by processes important for the stability of the watershed, for the maintenance of the quantity and quality of the water and for the maintenance of the aquatic ecosystem. One of the characteristics of riparian vegetation is the environmental heterogeneity that repeats itself within different vegetative domains, and ends up defining different methods for the study of riparian vegetation, studies such as that of plant phenology, fundamental in any vegetative plane; the phytosociological study, which allows the evaluation of vegetation structure and composition; the floristic, initial study for knowledge of flora; the dendrometry, which deals with the measurement of trees, both from the individual and collective points of view; and dendrological, which is based on knowing the species from specific regions, giving conditions for the knowledge of the tree structure of a given vegetation community. Therefore, the purpose of this work was to carry out a literature review presenting the main definitions of "riparian vegetation", its functions and conservation methods.
\end{abstract}

Keywords: Riparian forest; Functions; Methods for study.

\section{Topic: Botânica Agrícola e Ambiental}

Reviewed anonymously in the process of blind peer
Received: 14/07/2017

Approved: 13/10/2017
Sandra Aaparecida Anschau

Faculdade João Calvino, Brasil

http://lattes.cnpq.br/9492433756312279

a anschau@hotmail.com

Júlio Cesar Ibiapina Neres (iD

Faculdade Guaraí, Brasil

http://lattes.cnpq.br/9493252013144748

http://orcid.org/0000-0002-5277-0790

biologia@faculdadeguarai.com.br

Aluísio Vasconcelos Carvalho iD

Faculdade Guaraí, Brasil

http://lattes.cnpq.br/5200758055263996

http://orcid.org/0000-0002-3793-3133

aluisiovasconcelos@gmail.com

DOI: 10.6008/SPC2237-9290.2017.001.0003
Ana Paula Martins Guimarães

Faculdade Guaraí, Brasil

http://lattes.cnpq.br/5309168123830683

biologa.apmg@gmail.com

Liberta Lamarta Garcia Favoritto Neres

Faculdade Guaraí, Brasil

http://lattes.cnpq.br/0563097731032602

libertalamarta@gmail.com

Fernando Barnabé Cerqueira

Faculdade Guaraí, Brasil

http://lattes.cnpq.br/1604638349819259

fernando1.981@hotmail.com

\section{Referencing this:}

ANSCHAU, S. A.; NERES, J. C. I.; CARVALHO, A. V.; GUIMARÃES, A. P. M.; NERES, L. L. G. F.; CERQUEIRA, F. B.. Vegetação ripária e métodos de estudo. Natural Resources, v.7, n.1, p.19-32, 2017. DOI: http://doi.org/10.6008/SPC2237-9290.2017.001.0003 


\section{INTRODUÇÃO}

O Brasil se caracteriza por possuir uma enorme extensão territorial, grande variedade de climas, solos e grande diversidade biológica distribuídas nos vários tipos de formações vegetacionais. O conhecimento sobre a dinâmica dessas comunidades é de grande importância para sua conservação, pois estes remanescentes contêm populações de animais e plantas que, atualmente se tornaram raros ou em vias de extinção. O uso dos recursos florestais pelo homem provocou uma drástica redução das comunidades vegetais com características peculiares, comprometendo a sustentabilidade e a posterior manutenção da diversidade biológica (CARVALHO, 2017).

Apesar de tão necessária, a vegetação ripária vem desaparecendo rapidamente devido ao avanço desordenado da agricultura e o uso indiscriminado do solo. A degradação do solo é um dos principais problemas ambientais do planeta, além de ser obstáculo ao aumento sustentável da produtividade do agronegócio brasileiro, pois com a remoção da vegetação ripária para a implementação de lavouras e de pastagens, sem considerar a aptidão do solo e sem a adoção de práticas de manejo e técnicas de conservação de solo, além da destruição de hábitats, acelerou o processo erosivo e o assoreamento (ELMORE, 1992).

A vegetação ripária tem recebido atenção especial nos últimos anos devido à importância que representa especialmente para os cursos de água, pois o crescimento demográfico e o desenvolvimento socioeconômico são frequentemente acompanhadas de aumentos na demanda por água, cuja qualidade e quantidade são importantes para a saúde e o desenvolvimento de qualquer comunidade (KOBIYAMA, 2003).

A relação existente entre floresta ripária e recursos hídricos é um assunto discutido há muito tempo. Com o avanço científico e tecnológico, os conhecimentos sobre essa relação tiveram um significativo aumento, acelerando não somente a proteção florestal contra o desmatamento, mas também o reflorestamento (LIMA et al., 2000; LINDNER et al., 2003). Entretanto, muitas dúvidas ainda existem sobre essa relação, tais como o termo mais adequado para se referir a "faixa de vegetação" ao longo do curso de água, pois assim como os termos de uso popular, o uso incorreto desses termos também está consagrado na bibliografia científica e na legislação brasileira (RODRIGUES, 2000). Portanto, este trabalho teve por finalidade, realizar uma revisão bibliográfica apresentando as principais definições de "vegetação ripária", suas funções e as metodologias existentes para estudo vegetacionais.

\section{METODOLOGIA}

A heterogeneidade ambiental, característica das vegetações ripárias, somada ao fato dessas condições se repetirem dentro dos diferentes domínios vegetacionais acabam por definir diferentes métodos para o estudo das vegetações ripárias, dentre elas o estudo da fenologia de plantas, o estudo fitossociológico, o estudo florístico, o estudo de dendrometria e o estudo de dendrologia. 


\section{DISCUSSÃO TEÓRICA}

\section{Principais Definições de Vegetação Ripária}

Vem sendo discutida em diversas literaturas a definição da vegetação marginal que ocorre ao longo de cursos de água. Muitos autores utilizam denominações diferentes para falarem das mesmas definições, já outros utilizam as mesmas denominações para expressarem outras definições. Alguns termos utilizados para a designação de formações buscavam uma associação da fisionomia vegetacional com a paisagem regional, o que resultou em termos populares, que não expressavam a condição ecológica dominante.

De acordo com Rodrigues (2000) O termo ciliar foi usado inicialmente para designar as formações florestais observadas nos diques marginais de grandes planícies, numa faixa estreita de vegetação, geralmente isoladas da condição de interflúvio por extensas faixas de vegetação herbácea hidrófila (várzea). Portanto, florestas ciliares estão presentes em reservatórios, rios, represas e açudes numa estreita faixa de vegetação. De acordo com Meirelles et al. (2005), Mata Ciliar também é definido como estrutura vegetacional que acompanha o curso dos rios, córregos e ribeirões, e aquelas que se localizam em torno das represas, lagos e nascentes. Para Martins et al. (2003), a mata ciliar refere-se à vegetação florestal às margens de cursos de água, independentemente de sua extensão ou da região de ocorrência, ou ainda da sua composição florística. Kobiyama (2003) define mata ciliar como sendo uma faixa de mata ou composição florística às margens da água.

O termo ripário foi definido como vegetação relacionando-se, vivendo ou localizado nas margens de um curso de água natural seja um ribeirão, rio ou lago (ELMORE, 1992). Seria então, "vegetação ripária" o termo mais adequado para se referir a toda vegetação da margem, abrangendo além dos cursos de água naturais, os criados pelo homem, como as represas, e estando incluso qualquer tipo de vegetação (SOUZA, 1999). Já Rodrigues (1991), considera que o termo "floresta ripária" deve ser usado apenas para as formações sob interferência periódica da água no solo, na forma de encharcamento desse solo ou de inundação, responsável pela eliminação da serapilheira e do banco de sementes do solo, desta forma as florestas ripárias constituiriam as formações arbóreas das áreas ripárias. Kobiyama (2003), define floresta ripária como as formações com particularidade florística, em função das cheias periódicas, variáveis em intensidade, duração e frequência e da flutuação do lençol freático.

Além de floresta ripária, vegetação ciliar também se refere à vegetação do tipo florestal, como determinado por Barbosa et al. (2005) que se refere à vegetação ciliar como aquela que é observada conceitualmente como formações vegetacionais do tipo florestal que se encontram associadas aos cursos de água, ao longo dos quais podem estender-se por dezenas de metros a partir das margens e apresentar marcantes variações na composição florística e na estrutura comunitária.

Existem várias denominações para as formações vegetacionais que margeiam os cursos de água, sendo as mais frequentes, mata ciliar, floresta ripária, vegetação ripária, vegetação ciliar, floresta de galeria, entretanto, deve-se lembrar que a vegetação não é apenas representada pela formação florestal, mas 
também pelas formações que compõem as margens dos rios e ribeirões, sendo que as denominações que envolvem mata ou floresta refere-se a formações vegetacionais que acompanham o leito dos cursos de água.

Nos termos de uso popular, como mata ciliar, floresta ciliar, vegetação ciliar, floresta de galeria, entre outros, suas definições não atendem o princípio básico do sistema de nomenclatura fitogeográfica, que define que um termo só tem valor fitogeográfico quando sua aplicação é clara e seu significado é definido e delimitado, pois o termo "ciliar" é originado de cílio, significando proteção. Desta maneira, as florestas utilizadas para quebra-vento também poderiam ser mata ciliar. Entretanto, "ripária" significa "próximo ao curso de água", tratando de conceito de distância e água. Sendo assim, o termo ripário é mais correto do que o termo ciliar.

Assim como esses termos têm uso popular consagrado, o uso incorreto desses termos também está consagrado na bibliografia científica e na legislação brasileira, principalmente quando considerado que os remanescentes de vegetação ribeirinha são geralmente resultado de uma paisagem antrópica e não natural (RODRIGUES, 2000).

\section{Funções da Vegetação Ripária}

A floresta ripária é uma formação vegetacional de grande importância para a preservação dos ambientes naturais e a vida presente. É um conjunto de árvores, arbustos, entre outros, que se desenvolve com a função de isolar áreas próximas às margens dos rios, lagos e nascentes formando um ecótono ou zona de transição entre o ambiente aquático e o terrestre e mais ainda, estando, geralmente, entre o ambiente aquático e o ambiente antropizado pelo homem. Serve também como cobertura do sol deixando-o fofo como uma esponja, impedindo que as águas das chuvas escoem diretamente aos rios evitando erosões, assoreamentos e enchentes.

De acordo com Martins et al. (2003) a importância da presença de florestas ao longo dos rios e ao redor dos lagos e de reservatórios fundamenta-se nos múltiplos benefícios que este tipo de vegetação traz ao ecossistema, exercendo função protetora sobre os recursos bióticos e/ou abióticos.

Segundo Barbosa et al. (2005) dentre as principais funções da vegetação ripária está a proteção dos solos ribeirinhos contra a erosão através da resistência oferecida pelo emaranhado de raízes; proteção de mananciais; anteparo aos detritos carregados pelas enxurradas reduzindo os impactos sobre a vida aquática, a navegação e a qualidade da água para consumo humano e animal, geração de energia e irrigação; abastecimento do lençol freático pela suavização e contenção do impacto da água da chuva; auxílio à conservação da vida aquática, evitando alteração na topográfica submersa, propiciando algum controle da temperatura da água e fornecendo alimentos na forma de flores, frutos e insetos para a biodiversidade local.

Além das funções citadas anteriormente, as florestas ripárias podem proporcionar corredores ecológicos para as espécies encontradas nessas áreas, os quais desempenham um papel chave para a conservação da diversidade das espécies nesses ambientes (MEYER et al., 2004). Deve-se ainda somar a estas funções da vegetação ripária, a função hidrológica para a manutenção da integridade da microbacia hidrográfica, representada por processos importantes para a estabilidade da microbacia, para a manutenção 
da quantidade e qualidade de água, e manutenção do ecossistema aquático. A função hidrológica da floresta ripária é desempenhada através dos seguintes processos citados por Lima et al. (2000):

Geração do escoamento direto em microbacias: Escoamento direto é o volume de água que causa o aumento rápido da vazão de microbacias durante e imediatamente após a ocorrência de uma chuva. $O$ escoamento direto é basicamente produzido pelo escoamento superficial que acontece toda vez que a intensidade da chuva excede a capacidade de infiltração do solo, e toda água da chuva que se infiltra no terreno alimenta o lençol freático, deixando a microbacia na forma de escoamento base.

Por outro lado, as áreas parciais da microbacia, que são as zonas saturadas (que margeiam os cursos de água e suas cabeceiras), as concavidades do terreno (para as quais convergem às linhas de fluxo, como as concavidades frequentemente existentes nas cabeceiras) e as áreas de solo raso (com baixa capacidade de infiltração), podem produzir escoamento superficial mesmo quando a intensidade da chuva seja inferior a capacidade de infiltração média para a microbacia como um todo. Assim, somente uma parte da microbacia pode contribuir para o escoamento direto de uma chuva.

Quantidade de água: A vegetação ripária contribui com o aumento da capacidade de armazenamento de água em microbacias ao longo de zonas ripárias, colaborando com o aumento da vazão na estação seca do ano, ou seja, a destruição da vegetação ripária a médio e longo prazo, diminui a capacidade de armazenamento da microbacia, e como consequência a vazão na estação seca.

Qualidade da água: A vegetação ripária isola de forma estratégica o curso de água dos terrenos mais elevados da microbacia, desempenhando função eficaz de filtragem superficial de sedimentos, além de diminuir de maneira significativa, concentrações de herbicidas de microbacias tratadas com tais produtos.

Ciclagem de nutrientes: A maioria dos nutrientes liberados dos ecossistemas terrestres chega aos cursos de água através do transporte em solução no escoamento subsuperficial. Ao atravessar as zonas ripárias, esses nutrientes podem ser retidos por absorção pelo sistema radicular. $\mathrm{O}$ efeito de filtragem de nutrientes, proporcionado pela vegetação ripária confere estabilidade no processo de ciclagem geoquímica de nutrientes pela microbacia.

Interação direta com o ecossistema aquático: Em primeiro lugar, deve-se ressaltar a interação decorrente das raízes no papel desempenhado para a estabilização das margens. Em seguida, por abastecer o rio com material orgânico, com galhos e até troncos caídos. Os galhos e troncos, juntamente com a vegetação ripária, proporcionam a rugosidade das margens, favorecendo o processo de retenção, obstruindo o fluxo de água, criando zonas de turbulência e de velocidade diminuída, favorecendo o processo de deposição de partículas e sedimentos, criando micro-habitat favoráveis a alguns organismos aquáticos.

É de grande importância as funções desempenhadas pela vegetação ripária, sua drástica redução tem causado aumento significativo dos processos de erosão do solo, com prejuízos à hidrologia regional, evidente redução da biodiversidade e a degradação de imensas áreas, o que demanda a implantação ou recomposição das vegetações ripárias.

\section{Estudo da Fenologia de Plantas}

Carmo et al. (2000) ressalta a fenologia como o estudo da ocorrência de eventos biológicos repetitivos e das causas de sua ocorrência em relação às forças seletivas bióticas e abióticas e da inter-relação entre fases caracterizadas por estes eventos, numa mesma e em diferentes espécies. Segundo Bencke et al. (2002), a heterogeneidade dos estudos que abordam direta ou indiretamente a fenologia de plantas resulta na falta de padronização dos termos e dos métodos adotados, tanto para a coleta como para a análise dos dados, causando imprecisão na descrição dos padrões encontrados e dificultando a interpretação e comparação dos resultados. 
Além disso, as variações climáticas também influenciam a fenologia, regulando a época, a intensidade, a duração e a periodicidade dos eventos fenológicos (FERRAZ et al., 1998). A fenologia tem grande importância nas linhas da pesquisa ecológica, sendo considerada como um dos melhores parâmetros a ser utilizado para caracterizar ecossistemas. A observação fenológica reúne informações sobre estabelecimento de espécies, período de crescimento, reprodução, disponibilidade de recursos para polinizadores e dispersores, ciclagem de nutrientes permite uma visão integrada da dinâmica dentro de um ecossistema (CARMO et al., 2000).

Os ciclos fenológicos de plantas tropicais são complexos, pois apresentam padrões de difícil reconhecimento, principalmente em estudos de curto prazo. Sendo assim, a escolha dos métodos de avaliação e representação tem especial importância, pois podem tanto auxiliar como dificultar no reconhecimento dos padrões fenológicos. De acordo com Bencke et al. (2002), estudos fenológicos em florestas tropicais utiliza-se constantemente os métodos de avaliação qualitativa e a avaliação semiquantitativa.

O método de avaliação qualitativa define apenas a presença ou ausência da fenofase considerada. As fenofases são definidas pela floração - período em que as árvores apresentam as flores em antese (flores abertas); frutificação - período em que os frutos estão maduros e prontos para serem dispersos; brotamento; e queda foliar agrupando as populações em três categorias, de acordo com Bencke et al. (2002): decídua, semidecídua e perenifólia. A categoria decídua subdivide-se em: 1) Planta cujas folhas caem em certa época do ano; 2) Espécie vegetal que têm folhas caducas. A categoria semidecídua refere-se à perda de folhas em determinado período do ano, geralmente na seca; e 3) Produzem folhas continuamente independentes das estações do ano ou períodos de seca.

O método de avaliação semiquantitativa é definido pela aplicação de categorias de quantificação que estimam a intensidade do evento fenológico em cada indivíduo, sendo a mais comum a utilização de cinco categorias de quantificação (BENCKE et al., 2002). De acordo com Buzato et al. (2005), as cinco categorias de quantificação são de 0 a 4, com intervalo de $25 \%$ entre elas, normalmente avaliadas de acordo com a escala de Fournier (1974), sendo: 0 = ausência de fenofases; 1 = presença da fenofase com magnitude entre $1 \% \mathrm{e}$ $25 \%$; 2 = presença da fenofase entre $26 \%$ e $50 \%$; 3 = presença da fenofase entre $51 \%$ e $75 \%$; e $4=$ presença da fenofase entre $76 \%$ e $100 \%$.

O conhecimento fenológico é fundamental em qualquer plano vegetacional, seja na manutenção da vida silvestre, ou na produção de madeiras e outros recursos vegetacionais. Na ecologia e na evolução, a fenologia contribui para o entendimento da regeneração e reprodução das plantas, interações planta-animal e evolução dos animais que dependem de plantas para alimentação.

\section{Estudo Fitossociológico}

Os métodos fitossociológicos são ferramentas necessárias para o estudo da sociologia vegetal. Durigan et al. (2000) citam que os levantamentos fitossociológicos de comunidades florestais permitem uma caracterização da estrutura horizontal e mesmo vertical das comunidades florestais. O método mais utilizado 
para a caracterização da estrutura fitossociológica de vegetações ripárias é o método de parcelas, que permite o esclarecimento das correlações da vegetação com outros fatores ambientais, tanto físicos como bióticos e temporais, por reavaliações periódicas, quando usadas parcelas permanentes (DURIGAN et al., 2000).

Este método permite a ordenação das unidades amostrais com detecção dos agrupamentos de espécies e das correlações com as características do ambiente local, além de fornecer parâmetros quantitativos das espécies para cada situação ambiental identificada. $\mathrm{O}$ agrupamento das parcelas pode ser obtido através de métodos de classificação e ordenação utilizando matrizes dos dados de vegetação e físicos, disponíveis para as unidades amostrais, permitindo análises das similaridades florísticas entre as unidades, identificando agrupamentos e correlação com as condições abióticas locais.

O método de parcelas é mais eficiente na caracterização do mosaico vegetacional e no esclarecimento das correlações com as demais variáveis ambientais, é o que confirmam estudos comparativos utilizando o método de parcelas e o método de quadrantes para levantamento fitossociológico de florestas ciliares (OLIVEIRA, 2013; DURIGAN et al., 2000). O método de quadrantes possui maior eficiência na identificação da diversidade vegetal local, e deve ser recomendada para este objetivo.

Quando o objetivo do trabalho for à caracterização da estrutura fitossociológica do ecótono ciliar, a avaliação da eficiência amostral deve focar o conceito de associação ecológica, analisando se as comunidades constituintes do complexo ripário, definidas pelas variações fisiográficas locais, foram suficientemente caracterizadas em termos qualitativos e quantitativos.

No entanto, se o objetivo do trabalho for a identificação e discussão dos fatores reguladores da estrutura fitossociológica no ecótono ciliar, a avaliação da eficiência amostral deve priorizar as relações da comunidade com o ambiente, explicitando se as correlações do ambiente físico com as comunidades vegetacionais foram identificadas e se os processos reguladores do mosaico ambiental na constituição do ecótono ciliar foram devidamente representados na amostragem (DURIGAN et al., 2000).

Através da aplicação de um método fitossociológico pode ser feita uma avaliação da estrutura vegetacional, por meio da densidade (número de indivíduos, de uma dada espécie, por unidade de área), da dominância (taxa de ocupação do ambiente pelos indivíduos de uma espécie) e da frequência (probabilidade de se encontrar uma espécie em uma unidade de amostragem, seu valor estimado indica o número de vezes que a espécie ocorre, num dado número de amostras) das espécies que ocorrem em uma comunidade. Nenhum parâmetro isolado fornece uma ideia clara da comunidade ou das populações vegetais, mas em conjunto, podem caracterizar formações e subdivisões, suprir informações sobre estágios de desenvolvimento da comunidade e das populações, distribuir recursos ambientais entre populações, possibilitar a utilização de recursos vegetais etc. A qualidade e a quantidade dessas informações dependem dos parâmetros determinados e da extensão espacial e temporal dos estudos.

Entre os parâmetros fitossociológicos, os melhores métodos que permitem diferenciar formações vegetacionais e diferentes tipos fisionômicos são os que estão relacionados ao porte dos indivíduos (altura da planta, diâmetro do caule, área basal e biomassa) e a densidade, além da identificação dos componentes 
da flora. Os estudos fitossociológicos possibilitam a avaliação da estrutura e da composição da vegetação, permitindo assim, a derivação de informações e inferências relacionadas com a dinâmica ecológica da comunidade em análise.

\section{Ecótono ciliar}

Ecótono é definido por Odum (1988) como uma área de transição nítida entre duas ou mais comunidades diversas ou gradiente ecológico. Essa transição entre duas ou mais comunidades implica na existência de uma área com valores intermediários para os parâmetros que caracterizam a estrutura desse conjunto de organismos (densidade, cobertura, volume).

Este estado intermediário poderia surgir como resposta dos organismos às mudanças espaciais e/ou temporais de cada local ou hábitat ou, ser simplesmente consequência de um fator de dispersão tal como o fluxo de água, o vento ou outro agente que modifique o padrão espacial do conjunto. Observa-se certa dificuldade em determinar os limites do ecótono ripário. Souza (1999) discute essa questão considerando que, se esse limite se estende da marca máxima do pico de cheia à marca mínima do pico de vazante, incluindo toda a vegetação existente nessa área, o conceito é mais facilmente aplicável para riachos, enquanto que para rios, esse conceito ainda gera uma série de questionamentos, por exemplo, o rio Amazonas, que possui quilômetros quadrados de florestas inundáveis que o margeiam.

A transição poderia também ocorrer como consequência do contato de duas massas de água de procedência e qualidade distintas (como são as confluências dos rios), sem que as mudanças na distribuição das populações se produzam por ações de competição entre dois ou mais conjuntos. Trata-se de uma ação às taxas de mudanças das populações em contato.

Souza (1999) trata de questões relativas ao ecótono terra/água e à dinâmica hidrológica para melhor compreender as relações com o ecossistema aquático. Assim, em um conceito ecológico mais clássico, um rio é considerado um ecossistema aberto, tendo sua dinâmica altamente dependente da matéria orgânica e dos nutrientes que entram do sistema terrestre de captação. A quantidade, a qualidade e o tempo de suprimento de matéria orgânica ao ecossistema aquático são, portanto, altamente dependentes da estrutura da interface terra/água, isto é, do ecótono. Esse ecótono ao curso de água regula a entrada de nutrientes da bacia e o acesso de luz que afetam a geração de matéria orgânica.

Essas transições são mais efêmeras, inteiramente dependentes das características físicas dos fluxos de ambas as massas. A transição origina-se de diferenças físicas e/ou químicas do hábitat. Pode haver certa interferência (competição) entre as populações que integram a transição, mas é indireta pelos recursos do hábitat.

\section{Estudo Florístico}

Nas últimas décadas, houve considerável avanço nos estudos de comunidades florestais, principalmente por causa de sua importância para a conservação da diversidade biológica. A cada dia, essa importância se torna mais acentuada devido ao processo desordenado de ocupação do solo, em diversas 
regiões do país, tem transformado formações vegetacionais contínuas em fragmentos. A recuperação de ecossistemas degradados é uma atividade muito antiga. No entanto, até recentemente ela se caracterizava como uma atividade sem vínculos estreitos com concepções teóricas, sendo executada normalmente como uma prática de plantio de mudas, com objetivos muito específicos, como controle da erosão, estabilização de taludes, melhoria visual, entre outros (GANFOLDI et al., 2000).

A recuperação é, portanto, uma consequência do uso incorreto da paisagem e dos solos por todo o país, sendo apenas uma tentativa de remediar um dano que na maioria das vezes poderia ter sido evitado. A composição florística e a ecologia das comunidades arbóreas das vegetações ripárias são fundamentais para embasar quaisquer iniciativas no sentido de proteger, enriquecer, recuperar ou reconstruir áreas vegetacionais (NAVE et al., 2000; BOTEZELLI et al., 2003).

Segundo Gandolfi et al. (2000), no Brasil, importantes subsídios para a recuperação de áreas degradadas têm surgido de estudos de ecologia florestal nos diferentes ecossistemas impactados, onde se tem tratado de temas diversos, como a composição florística, a estrutura de comunidades, a dinâmica de clareiras, a regeneração natural, os parâmetros estruturais e genéticos de populações. Para a execução de projetos de restauração, é necessário conhecer o ecossistema onde se vão atuar, suas limitações e sua capacidade de recuperação, e para tanto se devem conhecer as composições florística e faunística, tanto em termos qualitativos como quantitativos, bem como as interdependências entre seus componentes.

O levantamento florístico é um dos estudos iniciais para o conhecimento da flora de uma determinada área (GODOY et al., 2001). Fornecem listas com a identificação taxonômica das espécies que ocorrem na formação vegetal e constituem a base para a execução de comparações qualitativas entre diferentes comunidades para a realização de estudos mais profundos sobre a estrutura e dinâmica dessas comunidades. Tem o intuito de distinguir as diferentes formações e fisionomias, além de contribuir com estudos fitogeográficos.

Já para Oliveira Filho et al. (2000)., levantamentos estritamente florísticos permitem comparações relativamente simples e eficientes entre muitas áreas. Porém, diferenças e semelhanças entre áreas geograficamente próximas e/ou floristicamente parecidas podem ser melhor abordadas através de dados quantitativos fornecidos por levantamentos fitossociológicos, essas diferenças quantitativas entre áreas podem ser muito mais marcantes que diferenças florísticas.

Para Godoy et al. (2001), em áreas demarcadas, o levantamento florístico abre perspectivas para o desenvolvimento de pesquisas relacionadas à fitossociologia, à fenologia e à dinâmica das populações ali instaladas. Vários estudos têm mostrado que um dos principais fatores que atuam na composição florística e na estrutura da vegetação são as heterogeneidades ambientais, cujos efeitos podem ser observados mesmo no interior de pequenos fragmentos. Essa heterogeneidade é resultado da diversidade de fatores que interagem nas comunidades e a resposta das espécies a esses fatores faz com que cada local tenha características próprias e características que são comuns a outros locais, possibilitando observar tendências.

Segundo Nave et al. (2000), os fatores promotores da heterogeneidade florística podem ser o tamanho da faixa ripária florestal, o estado de conservação de remanescentes, o tipo vegetacional de origem 
da formação florestal, a matriz vegetacional onde a formação florestal está inserida, o acaso na chegada de dissemínulas no processo de estabelecimento das formações florestais, e principalmente, a heterogeneidade vegetacional como resultado da heterogeneidade espacial das características físicas do ambiente ciliar e de outros fatores atuantes na seleção de espécies.

Para eles, ignorar essa complexidade ambiental durante a escolha e distribuição de espécies vegetacionais nos projetos de recuperação de áreas ripárias pode resultar numa homogeneização artificial da vegetação ripária, com consequências imprevisíveis na dinâmica e diversidade ecológica dessas áreas, principalmente em regiões onde as áreas ripárias aparecem muito fragmentadas. Sendo assim, a escolha adequada das espécies que deverão ser usadas na recuperação de uma dada área, representa a principal, ou uma das principais garantias de sucesso da recuperação. A escolha das espécies deve levar em consideração as diferenças de adaptação das espécies para cada condição ambiental.

\section{Estudo de Dendrometria}

A dendrometria é um ramo da ciência florestal que trata da medição de árvores, tanto do ponto de vista individual quanto do coletivo (SILVA et al., 2005). De acordo com o mesmo autor, em virtude da crescente valorização da madeira como matéria-prima e como produto, a busca de estimativas precisas de volumes de madeira tem ganhado destaque e importância. Desta forma, a dendrometria é aplicada com objetivos comerciais, visando estimar com precisão o que se retira das florestas na compra e venda de material.

Além do objetivo comercial, a dendrometria pode ser aplicada com o objetivo de ordenamento, quando na exploração do produto florestal, deve-se ter em mente o rendimento sustentável, onde o que se retira deve equivaler ao que cresce na mesma área (para atingir este objetivo deve-se elaborar planos de ordenamento florestal a longo prazo, e para isso é preciso conhecer o desenvolvimento da floresta, por espécies e locais), e com objetivo de pesquisa, para determinar com precisão o desenvolvimento de uma floresta, usando técnicas especiais que avançam sem parar em outras condições, o que exige a pesquisa detalhada sobre a sua adaptabilidade ou a busca de novas técnicas de aplicação específicas.

Em dendrometria, o termo cubagem ou cubicagem designa o cálculo do volume do material lenhoso de uma árvore, uma pilha ou um povoamento florestal, sendo utilizados para métodos de medição direta, indireta, estimativa equacional, entre outros (PINTO et al., 2005). Segundo Couto et al. (1979), os métodos de medição direta são aqueles que podem ser utilizados em povoamentos jovens, quando, devido à pouca altura, as árvores podem ser facilmente mensuradas. Os métodos de medição indireta são aplicados para florestas de maior porte. Dentre os instrumentos utilizados para este método pode-se citar a Prancheta dendrométrica, Hipsômetro de Christen, Hipsômetro de Haga, Hipsômetro de Blume-Leiss e Hipsômetro de Weise. Os métodos de medição estimada são baseados em métodos estatísticos, feitas na árvore ou no povoamento. É um método bastante utilizado pelo fato de ser econômico e rápido, pois são feitos em amostras que estimam o todo através de curvas, equações e tabelas. 
Para qualquer medida ou estimativa estão sujeitos erros, que podem ser reduzidos se empregados bons instrumentos. Os tipos de erros podem ser classificados em erros compensantes, que independem do operador e é mais comum quando usado aparelhos com menor exatidão (se utilizado um instrumento de precisão em cm, cometerá um erro compensante maior do que se utilizar um instrumento graduado em mm, não precisando fazer arredondamentos), erros de estimação, são erros cometidos quando utilizada amostragem para estimar a população (na prática florestal, utiliza-se muito o limite de confiança, que não dá valores médios exatos, mas dá um espaço limitado onde o valor real deverá se enquadrar, por exemplo: a altura média da população igual a $18,7 \pm 1,8 \mathrm{~m}$, o que quer dizer que a altura média deve estar entre $16,9 \mathrm{~m}$ e 20,5m, a uma probabilidade determinada), e erros sistemáticos, que são mais comuns, causados por defeitos nos instrumentos ou pela falta de habilidade do operador para manuseá-lo.

Segundo Tonini et al. (2005) os trabalhos dendrométricos são relacionados com espécies introduzidas, de rápido crescimento. As espécies nativas muitas vezes deixam de ser estudadas por não conseguirem despertar interesse equivalente, na maioria das vezes, pela inexistência de informações relativas à sua ecologia, silvicultura e biometria.

\section{Estudo de Dendrologia}

De acordo com Almeida et al. (2000), não existe consenso quanto à definição de dendrologia. Pode ser tomada como taxonomia das árvores, neste caso o dendrólogo seria um especialista em botânica taxonômica que lida com as árvores. Pode abranger só a identificação das árvores, neste caso o dendrólogo lidaria com os procedimentos mais eficientes para identificar as árvores mesmo no campo utilizando as características macroscópicas dos órgãos vegetativos.

O levantamento dendrológico tem como base conhecer as espécies a partir de regiões específicas pela facilidade de trabalhos e pela importância que tem no contexto florestal. É o início de uma ampla e complexa ação de pesquisa que visa, por meio de outros estudos e projetos específicos, conhecer as florestas nativas a fim de possibilitar o seu manejo racional e conhecer as árvores exóticas introduzidas nas regiões de estudo (PINHEIRO et al., 2000).

É o levantamento dendrológico que dá condições para o conhecimento da constituição arbórea de uma determinada comunidade vegetacional e as características das espécies que compõe a área.

Segundo Galvão et al. (2002) O levantamento dendrológico pode ser aplicado em vários tipos de situações, podendo envolver áreas pequenas (no máximo até 1,0 ou 2,0 hectares), como vegetações ripárias de determinados locais, matas protetoras de nascentes, logradouros públicos, bosques, capões, pequenos remanescentes de algumas propriedades, etc. até áreas extensas com diversos tipos fisionômicos de vegetações.

Ainda para Roderjan (1987), o levantamento dendrológico deve ter como objetivos fundamentais a identificação das espécies, localização em croqui dos indivíduos, descrição dendrológica das espécies e chaves de reconhecimento das árvores no campo (dados obtidos no campo viabilizam a definição de índices de frequência, índices de valores de importância, dominância e abundância das espécies). 
O Inventário florestal diferencia-se do levantamento dendrológico por ter por objetivo principal quantificar o volume de madeira dos indivíduos arbóreos, com a finalidade de avaliação e exploração (ALMEIDA et al., 2000).

Segundo Cesaro et al. (1994) os métodos usados para inventariar populações vegetacionais buscam o menor erro para uma mesma quantidade de trabalho, fixada a precisão desejada para as informações a serem levantadas.

O método mais antigo, segundo o mesmo autor, é realizado em uma área fixa. Neste método a seleção das árvores ocorre com probabilidade proporcional à área, pois todas as áreas que se situarem no interior de uma unidade de amostra serão medidas. Mas este método possui também desvantagem, pois povoamentos jovens ou de espaçamento reduzido terão medidos um maior número de árvores para representar um volume pequeno do que em um povoamento velho e que apresente maior volume. Assim vegetações jovens que apresentam baixo volume serão medidas com muito mais precisão do que povoamentos com grande volume.

Existe também o método das 6 árvores, neste método não ocorre o problema de representatividade do número de árvores já que o tamanho das unidades de amostras é variável, de acordo com a distância entre o centro da unidade e o centro da sexta árvore mais próxima a este ponto de referência. Este método gera unidades de área circular sendo o método de seleção das árvores por meio de probabilidade proporcional à distância.

Segundo Cesaro et al. (1994) outro método de área variável, no qual a seleção das árvores que compõem a unidade de amostra é de probabilidade proporcional ao tamanho, é o método desenvolvido por Bitterlich em 1948. Neste método, a seleção das árvores que compõem a unidade de amostra é realizada pela comparação do diâmetro da árvore com um ângulo de visada constante.

Para BEERS et al. (1982) qualquer que seja a forma e tamanho da unidade amostral, será possível calcular o volume de madeira da vegetação sem erros sistemáticos, porém dadas certas características vegetacionais a extensão e a forma ótima das unidades amostrais variam. Sendo assim, ao planejar um inventário florestal, deve ser estudado o tamanho e a forma ideais para a população, através da comparação do número de unidades e custos correspondentes, buscando identificar aquela que proporcione a mesma informação com o mínimo de custo, com o mesmo erro de amostragem entre as formas e tamanhos comparados.

\section{CONSIDERAÇÕES FINAIS}

Tendo a vegetação ripária recebido especial atenção nos últimos anos devido à importância para os cursos de água, cuja qualidade e quantidade são importantes para a saúde e o desenvolvimento de qualquer comunidade, pode-se concluir revisando-se as terminologias utilizadas para definir a vegetação marginal que ocorre ao longo de cursos de água, que o termo ripário é o mais adequado para se referir a vegetação da margem, abrangendo além dos cursos de água naturais, os criados pelo homem. 
A vegetação ripária tem várias funções, dentre elas, a proteção dos solos ribeirinhos contra a erosão, devido à resistência oferecida pelo emaranhado de raízes, retendo impurezas e preservando a integridade das águas, sendo esta utilizada por espécies não florestais. A heterogeneidade ambiental que é uma das características das vegetações ripárias, define diferentes metodologias para o estudo dessas vegetações, os quais devem ser analisados antes de ser aplicados em determinadas condições.

Mesmo constatando que em praticamente todos os Estados brasileiros tenha ocorrido uma redução das vegetações ripárias devido à expansão agrícola, às pastagens, ao aproveitamento hidrelétrico, entre outros, a Legislação Brasileira assegura a proteção das áreas de preservação permanentes e áreas de reserva legal, estabelecendo leis com vigência para todo o território nacional.

\section{REFERÊNCIAS}

ALMEIDA, E. C.; PINHEIRO, A. L.. Fundamentos de taxonomia e dendrologia tropical: Metodologia dendrológica. Viçosa: Execução Jardim, 2000.

ARCO-VERDE, M. F.; SÁ, S. P. P.; TONINI, H.. Dendrometria de espécies nativas em plantios homogêneos no Estado de Roraima - Andiroba (Carapa guianensis Aubl), Castanha-do-Brasil (Bertholletia excelsa Bonpl.), Ipê-roxo (Tabebuia avellanedae Lorentz ex Griseb) e Jatobá (Hymenaea courbaril L.). Acta Amazônica, Manaus, v.35, n.3, 2005.

ARTES, R.; FERRAZ, D.K.; MAGALHÃES, L.M.; MANTOVANI, W.. Fenologia de Árvores em Fragmento de Mata em São Paulo. Revista Brasileira de Biologia, São Carlos, v.59, n.2, 1998.

BARBOSA, F. M.; LACERDA, A. V.; NORDI, N.; WATANABE, T.. Levantamento florístico do componente arbustivo-arbóreo da vegetação ciliar na bacia do rio Taperoá. Acta Botânica Brasileira, Pampulha, v.19, n.3, 2005.

BEERS, T. W.; HUSCH, B.; MILLER, C. I.. Forest mensuration. New York: John Wiley \& Sons, 1982.

BENCKE, C. S. C.; MORELLATO, L. P.. Comparação de dois métodos de avaliação da fenologia de plantas, sua interpretação e representação. Revista Brasileira de Botânica. São Paulo, v.25, n.3, 2002.

BENCKE, C. S. C.; MORELLATO, L. P.. Estudo comparativo da fenologia de nove espécies arbóreas em três tipos de floresta atlântica no sudeste do Brasil. Revista Brasileira de Botânica, São Paulo, v.25, n.2, 2002.

BOTEZELLI, L.; ESPÍRITO-SANTO, F. D. B.; FONTES. M. A. L.; OLIVEIRA-FILHO, A. T.; SOUZA, J. S.. Análise das variações florísticas e estruturais da comunidade arbórea de um fragmento de floresta semidecídua às margens do rio Capivari. Revista Árvore, Viçosa, v.27, n.2, 2003.

BUENO, M. C. D.; COUTINHO, H. L. C.; DIAS, T. C. S.; MEIRELLES, M. S. P.. Sistema de suporte a decisão para avaliação do risco de impactos ambientais em bacias hidrográficas por redes de dependência e lógica fuzzy. In: SIMPÓSIO BRASILEIRO DE SENSORIAMENTO REMOTO, 12. Anais. Goiânia, 2005.

BUZATO, S.; LOPES, L. E.. Biologia reprodutiva de Psychotria suterella Muell. Arg. (Rubiaceae) e a abordagem de escalas ecológicas para a fenologia de floração e frutificação. Revista Brasileira de Botânica, São Paulo, v.28, n.4, 2005.

CARMO, M. R. B.; MORELLATO, L. P.. Fenologia de Árvores e arbustos das Matas Ciliares da Bacia do Rio Tibagi, Estado do Paraná, Brasil. In: Matas Ciliares: conservação e recuperação. São Paulo: Edusp, 2000.

CARVALHO, I. C. M.. Educação Ambiental: Quem é o alvo?. Revista EcoDebate, Rio de Janeiro, 2017.

CESARO, A. D.; ENGEL, O. A.; GUIMARÃES, C. A.; SCHNEIDER, P. R.; Comparação dos métodos de amostragem de área fixa, relascopia, e de seis árvores, quanto a eficiência, no inventario florestal de um povoamento de Pinus sp. Universidade Federal de Santa Maria, Santa Maria, v.4, n.1, 1994.

COUTO, H. T. Z.; FERRARI, M. P.. O Hipsômetro do IPEF/CEF - ESALQ. Circular Técnica, Brasília, n.53, 1979.

DURIGAN, G.; RODRIGUES, R.R.; SCHIAVINI, I.. A Heterogeneidade Ambiental Definindo a Metodologia de Amostragem da Floresta Ciliar. In: Matas Ciliares: conservação e recuperação. São Paulo: Edusp, 2000.

ELMORE, W.. Riparian responses to grasing practices. In: Watershed management: balancin sustainability 
and enviromental change. New York: Springer-Verlag, 1992.

GALVÃO, F.; HATSCHBACH, G. G.; KUNIYOSHI, Y. S.; RODERJAN, C. V.. As unidades fitogeográficas do Estado do Paraná. Ciência \& Ambiente, Curitiba, v. 24, 2002.

GANDOLFI, S.; RODRIGUES, R. R.. Conceitos, Tendências e Ações para a Recuperação de Florestas Ciliares. In: Matas Ciliares: conservação e recuperação. São Paulo: Edusp, 2000.

GODOY, S. A. P.; WEISER, V. L.. Florística em um hectare de cerrado Stricto sensu na Arie - cerrado Pé de - Gigante, Santa Rita do Passa Quatro, SP. Acta botânica brasileira. Pampulha, v.15, n.2, 2001.

JUNIOR, P. M.; MEYER, S. T.; NETO, J. A. A. M.; SILVA, A. F.. Composição florística da vegetação arbórea de um trecho de floresta de galeria do Parque Estadual de Rola-Moça na Região Metropolitana de Belo Horizonte. Acta Botânica Brasileira, Pampulha, v.18, n.4, 2004.

KOBIYAMA, M.. Conceitos de zona ripária e seus aspectos geobiohidrológicos. In: SEMINÁRIO DE HIDROLOGIA FLORESTAL: ZONAS RIPÁRIAS. Anais. Alfredo Wagner, 2003.

LIMA, W. P.; ZAKIA, M. J. B.. Hidrologia de Matas Ciliares. In: Matas Ciliares: conservação e recuperação. São Paulo: Edusp, 2000.

LINDNER, E. A.; SILVEIRA, N. F. Q.; A Legislação Ambiental e as áreas ripárias. In: SEMINÁRIO DE HIDROLOGIA FLORESTAL: ZONAS RIPÁRIAS. Anais. Alfredo Wagner, 2003.

MARTINS, S. S.; SILVA, I. C.; SILVA, O. H.; TORMENA, C. A.; VEIGA, M. P.. Avaliação dos aspectos florísticos de uma mata ciliar no Norte do Estado do Paraná. Acta
Scientiarum, Maringá, v.25, n.2, 2003.

NAVE, A. G.; RODRIGUES, R. R.. Heterogeneidade Florística das Matas Ciliares. In: Matas Ciliares: conservação e recuperação. São Paulo: Edusp, 2000.

ODUM, E. P.. Ecologia. Rio de Janeiro: Guanabara Koogan S.A., 1988.

OLIVEIRA, E. A.. Caracterização florística, fitossociológica e pedológica de um trecho da floresta ripária dos Campos Gerais do Paraná. Dissertação (Mestrado em Engenharia Florestal) Universidade Federal do Paraná, Curitiba, 2013.

OLIVEIRA-FILHO, A. T.; VAN DEN BERG, E.. Composição florística e estrutura fitossociológica de uma floresta ripária em Itutinga, MG, e comparação com outras áreas. Revista Brasileira de Botânica, São Paulo, v.23, n.3, 2000.

PINTO, F. A. C.; RIBEIRO, C. A. A. S.; SILVA, M. C.; SOARES, C. P. B.; SOARES, V. P.. Determinação do volume de madeira empilhada através de processamento de imagens digitais. Scientia Forestalis, n.69, 2005.

RODERJAN, C. U.. Dendrologia: introdução, terminologia e metodologia. Curitiba: 1987.

RODRIGUES, R. R.. Análise de um remanescente de vegetação natural às margens do rio Passa Cinco. Tese (Doutorado em Biologia Vegetal) - Universidade Estadual de Campinas, Campinas, 1991.

RODRIGUES, R. R.. Florestas Ciliares?. In: Matas Ciliares: conservação e recuperação. São Paulo: Edusp, 2000.

SOUZA, M. C.. Algumas considerações sobre vegetação ripária. Cadernos da Biodiversidade, Curitiba, v.2, n.1, 1999. 